\title{
Latitudinal and seasonal variations of lower atmospheric inertial gravity wave energy revealed by US radiosonde data
}

\author{
S. D. Zhang ${ }^{1,2,3}$, F. Yi ${ }^{1,2,3}$, C. M. Huang ${ }^{1,2,3,4}$, and Q. Zhou ${ }^{4}$ \\ ${ }^{1}$ School of Electronic Information, Wuhan University, Wuhan, Hubei, China \\ ${ }^{2}$ Key Laboratory of Geospace Environment and Geodesy, Ministry of Education, Wuhan, Hubei, China \\ ${ }^{3}$ State Observatory for Atmospheric Remote Sensing, Wuhan, China \\ ${ }^{4}$ Electrical and Computer Engineering Department, Miami University, Oxford, OH45056, USA
}

Received: 19 November 2009 - Revised: 24 February 2010 - Accepted: 3 May 2010 - Published: 6 May 2010

\begin{abstract}
The latitudinal and seasonal variations of gravity wave $(\mathrm{GW})$ potential energy density $\left(E_{\mathrm{P}}\right)$, kinetic energy density $\left(E_{\mathrm{K}}\right)$, and total energy density $\left(E_{\mathrm{T}}\right)$, i.e, the sum of potential and kinetic energy densities in the tropospheric (typically $2-10 \mathrm{~km}$ ) and lower stratospheric (typically 18 $25 \mathrm{~km})$ segments have been derived from 10 years $(1998$ 2007) of radiosonde observations over 92 United States stations in the Northern Hemisphere. The latitudinal variation of $E_{\mathrm{P}}$ in the lower stratosphere is in good agreement with satellite observations. However, $E_{\mathrm{K}}$ and $E_{\mathrm{T}}$ in the lower stratosphere are different from satellite observations and the difference is believed to be linked with the latitudinal dependence of GW sources. Our analysis reveals that GW energy properties exhibit distinctive latitudinal and seasonal variations. The upward-propagating GW energy in the troposphere is larger than that in the lower stratosphere at low latitudes but the opposite holds true at high latitudes. The transition latitude, where the upward- propagating energies in the two altitude regions are the same, occurs at $35^{\circ} \mathrm{N}$ throughout the year. So striking differences between GW activity in the troposphere and lower stratosphere are not likely explained only by the background wind Doppler shifting due to strong tropospheric jets. Our analysis indicates that the region around tropopause, roughly from $10 \mathrm{~km}$ to $18 \mathrm{~km}$, is an important source region, especially at latitudes below $35^{\circ} \mathrm{N}$. Our studies strongly suggest that in order to fully understand the global GW activity in the lower atmosphere, the GW kinetic energy and its geographical and seasonal variations should be included, and more attention should be given to GWs in the troposphere and GW sources within the intermediate region, especially the upper troposphere.
\end{abstract}

Correspondence to: S. D. Zhang (zsd@whu.edu.cn)
Keywords. Meteorology and atmospheric dynamics (Middle atmosphere dynamics)

\section{Introduction}

Decades of observations and simulations have revealed the key role of gravity waves (GWs) in determining the local and global dynamic and thermal structures of the middle and upper atmosphere by dissipating their energy and momentum in the background atmosphere through various complex processes. In modeling global scale atmospheric dynamics, the effects of GWs must be parameterized to obtain realistic mean atmospheric circulations and thermal structures. However, the parameterized GW effects are believed to be major sources of uncertainties in model predictability and reliability. Numerical experiments suggested that different wave source parameterizations could lead to rather different results (Manzini and McFarlane, 1998) and an appropriate source parameterization is essential in developing a good wave drag parameterization. Lack of observations, especially global observations, is one of the primary limitations in developing and verifying $\mathrm{GW}$ source parameterizations. The lower atmosphere, especially the troposphere, is believed to be the main source region of GWs propagating in the middle and upper atmosphere. Thus, observations of lower atmospheric GWs are important in extending our knowledge of atmospheric GWs and their impacts on the background atmospheric dynamic and thermal structures.

Satellite observations have contributed significantly to our understanding of global gravity waves (GWs) in the lower atmosphere (Fetzer and Gille, 1994; Wu and Waters, 1996; Eckermann and Preusse, 1999; McLandress et al., 2000; Tsuda et al., 2000; Venkat Ratnam et al., 2004; Fröhlich

Published by Copernicus Publications on behalf of the European Geosciences Union. 
et al., 2007; Alexander et al., 2008; Hei et al., 2008). A salient result revealed by these satellite observations is that the lower stratospheric GW energy exhibited a prominent peak (maximum absolute value) in the low latitudinal region. A seasonal cycle of GW energy can be observed in middle latitudes (Tsuda et al., 2000). Such a lower latitudinal peak (maximum absolute value) was supported by multistation radiosonde observations (Allen and Vincent, 1995; Wang and Geller, 2003; Wang et al., 2005). It should be noted that because of the difficulties in lower atmospheric wind field measurements, most of the above cited satellite observations took the GW potential energy density $\left(E_{\mathrm{P}}\right)$, estimated from the temperature measurement, as an indicator of total gravity wave energy density $\left(E_{\mathrm{T}}\right)$, i.e., the sum of potential and kinetic energy densities $\left(E_{\mathrm{K}}\right)$. That is to say that the peak of GW energy in low latitudes revealed by satellite observations in fact indicated only the peak of $E_{\mathrm{P}}$ rather than that of $E_{\mathrm{T}}$. Although the GW kinetic energy can be estimated from wind profiles by radiosonde observations, unfortunately, some multi-station radiosonde observations (e.g., Allen and Vincent, 1995) focus mainly on the potential energy and little attention has been paid to the wave kinetic energy and total energy. Wang and Geller (2003) have investigated both $E_{\mathrm{P}}$ and $E_{\mathrm{K}}$ from 4 years (1998-2001) of US high vertical resolution radiosonde observations over more than 90 stations and found that $E_{\mathrm{T}}$ of stratospheric GWs have very large value sin winter in middle latitudes. Recently, Zhang and Yi (2007) analyzed the radiosonde observations from five stations located in latitudes of $20^{\circ} \mathrm{N}-40^{\circ} \mathrm{N}$ and found that although the $E_{\mathrm{P}}$ has a maximum value at Haikou station $\left(110^{\circ} 12^{\prime} \mathrm{E}, 20^{\circ} 12^{\prime} \mathrm{N}\right)$, which is in the lowest latitude among these five stations, the $E_{\mathrm{K}}$ and $E_{\mathrm{T}}$ exhibited maximum value in latitudes about $30^{\circ} \mathrm{N}$ due to the strong tropospheric jet, which is thought to be an important GW source. Thus, a question arises: Do the kinetic energy and the total energy in the lower stratosphere really have completely identical latitudinal and seasonal variations as those of the potential energy?

Radiosonde observations can measure both the lower atmospheric temperature and horizontal winds with high resolution, which allow us to simultaneously estimate $E_{\mathrm{P}}$ and $E_{\mathrm{K}}$. Moreover, radiosonde observations usually have wide land coverage and long term accumulation, thus, multistation radiosonde observations should be favorable to reveal the latitudinal variation of GW energy densities. Up to now several multi-station radiosonde observations have been reported (Allen and Vincent, 1995; Wang and Geller, 2003; Wang et al., 2005; Zhang et al., 2006; Zhang and Yi, 2007; Gong et al., 2008). However, some limitations of these previous observations should be noted: 1) Narrow latitude coverage or too few stations were included. In the study by Zhang et al. (2006) and Zhang and Yi (2007), data from only 5 stations in latitudes $20^{\circ} \mathrm{N}-40^{\circ} \mathrm{N}$ were included. 2) Relatively short-term data accumulation. Allen and Vincent (1995) analyzed only 2 years data from 18 stations in latitudes $12^{\circ} \mathrm{S}-68^{\circ} \mathrm{S}$. 3) Concentrated mainly on wave potential energy rather than the total energy density (Allen and Vincent, 1995). In these studies, the total energy density $E_{\mathrm{T}}$ was estimated from only the normalized temperature fluctuations (Allen and Vincent, 1995) by applying a linear GW spectral theory, in which a constant spectral index $p$ of $5 / 3$ is used. Furthermore, aside from of these limitations, the multi-station radiosonde observations are generally sparse.

Another question is what role tropospheric GWs play in determining the middle and upper atmospheric dynamics. Previous radiosonde observations at equatorial stations (Vincent and Alexander, 2000) suggested upward-propagating waves excited in the troposphere had no significant influences on the upper atmospheric dynamics due to the absorption by the tropospheric jet, and only the stratospheric GWs might propagate upward and exert a profound impact on the dynamic and thermal structures of the middle and upper atmosphere. However, by using multi-station radiosonde data, Wang and Geller (2003) analyzed GW energy in both troposphere and lower stratosphere and suggested the time series of tropospheric GW energies is virtually uncorrelated with that in the lower stratosphere. Furthermore, Zhang and Yi (2007) carefully compared the parameters of GWs in the troposphere and lower stratosphere (TLS) and found that the differences of GWs in these two height regions could not be completely explained by linear gravity wave dispersion relation and background wind Doppler shifting. Recently, Gong et al. (2008) investigated the source spectra information for GWs in the lower stratosphere by using multi-station US radiosonde data. Moreover, numerical studies (Manzini and McFarlane, 1998) emphasized the importance of further understanding of the characteristics of GW activity in their source regions, which are believed to be located mainly in the troposphere instead of the stratosphere.

This paper is a study extending the work of Wang and Geller (2003) and Wang et al. (2005) with the benefit of an extended data set. The purpose of this paper is to study the latitudinal and seasonal variations of total GW energy density in both the troposphere and lower stratosphere by analyzing routine radiosonde data in a wide geographical region. The data description and processing method are introduced in the following section. The statistical results and discussions are presented in Sects. 3 and 4, respectively. In the last section, we give a brief summary.

\section{Data description and analysis method}

The data used in this paper are the United States radiosonde data in 1998-2007 obtained from National Oceanic and Atmospheric Administration (NOAA) National Climatic Data Center (NCDC). These data are freely accessed through the Stratospheric Processes and Their Role in Climate Data Center (http://www.sparc.sunysb.edu/). There are 93 stations in total, located across the contiguous United States, Alaska, 
Table 1. The station names, latitudes $\left({ }^{\circ} \mathrm{N}\right)$, longitudes $\left({ }^{\circ} \mathrm{E}\right)$ and available data accumulations (years) of the 92 US stations.

\begin{tabular}{|c|c|c|c|c|c|c|c|}
\hline Station & Lat & Lon & $\begin{array}{l}\text { Available } \\
\text { data }\end{array}$ & Station & Lat & Lon & $\begin{array}{l}\text { Available } \\
\text { data }\end{array}$ \\
\hline Ponape Island & 6.97 & 158.22 & 10 & Topeka, KS & 39.07 & -95.62 & 10 \\
\hline Koror/Palau Island & 7.33 & 134.48 & 10 & Wilmington, $\mathrm{OH}$ & 39.42 & -83.82 & 10 \\
\hline Truk Intl/Moen Island & 7.47 & 151.85 & 10 & Reno, NV & 39.57 & -119.8 & 9 \\
\hline Yap Island & 9.48 & 138.08 & 10 & Denver/Stapleton Airport, CO & 39.77 & -104.88 & 10 \\
\hline Guam, Mariana Island & 13.55 & 144.83 & 10 & Pittsburgh/Moon Township, PA & 40.53 & -80.23 & 10 \\
\hline Belize City & 17.53 & -88.3 & 6 & Salt Lake City, UT & 40.77 & -111.97 & 8 \\
\hline San Juan/Isla Verde, PR & 18.43 & -66 & 10 & Brookhaven, NY & 40.87 & -72.87 & 10 \\
\hline Grand Cayman & 19.3 & -81.37 & 4 & Elko, NV & 40.87 & -115.73 & 9 \\
\hline Hilo, HI & 19.72 & -155.07 & 10 & North Platte, NE & 41.13 & -100.68 & 10 \\
\hline Brownsville, TX & 25.9 & -97.43 & 10 & Medford, OR & 42.37 & -122.87 & 10 \\
\hline Tampa Bay Area/Ruskin, FL & 27.7 & -82.4 & 10 & Detroit/Pontiac, MI & 42.7 & -83.47 & 10 \\
\hline Corpus Christi, TX & 27.77 & -97.5 & 7 & Buffalo/Grenter Airport, NY & 42.93 & -78.73 & 9 \\
\hline Del Rio, TX & 29.37 & -100.92 & 10 & Riverton, WY & 43.06 & -108.47 & 9 \\
\hline Lake Charles, LA & 30.12 & -93.22 & 9 & Boise, ID & 43.57 & -116.22 & 9 \\
\hline Slidell, LA & 30.33 & -89.82 & 10 & Gray, ME & 43.89 & -70.25 & 9 \\
\hline Tallahassee, FL & 30.38 & -84.37 & 9 & Rapid City, SD & 44.07 & -103.21 & 9 \\
\hline Jacksonville, FL & 30.43 & -81.7 & 9 & Green Bay, WI & 44.48 & -88.13 & 10 \\
\hline Santa Teresa, NM & 31.9 & -106.7 & 10 & Gaylord/Alpena, MI & 44.55 & -84.43 & 10 \\
\hline Midland, TX & 31.93 & -102.2 & 8 & Chanhassen, MN & 44.83 & -93.55 & 8 \\
\hline Tucson, AZ & 32.12 & -110.93 & 10 & Salem, OR & 44.92 & -123.02 & 10 \\
\hline Peachtree City, GA & 33.35 & -84.56 & 10 & Glasgow, MT & 48.2 & -106.62 & 10 \\
\hline Morehead City/Newport, NC & 34.7 & -76.8 & 10 & International Falls, MN & 48.57 & -93.38 & 10 \\
\hline North Little Rock, AR & 34.83 & -92.27 & 10 & Annette Island, $\mathrm{AK}$ & 55.03 & -131.57 & 10 \\
\hline Albuquerque, NM & 35.05 & -106.62 & 10 & Cold Bay, AK & 55.2 & -162.72 & 10 \\
\hline Norman, OK & 35.23 & -97.47 & 9 & St. Paul Island, AK & 57.15 & -170.22 & 10 \\
\hline Amarillo, TX & 35.23 & -101.7 & 9 & Kodiak, AK & 57.75 & -152.48 & 10 \\
\hline Flagstaff/Bellemt(Army), AZ & 35.23 & -111.82 & 9 & King Salmon, AK & 58.68 & -156.65 & 10 \\
\hline Greensboro, NC & 36.08 & -79.95 & 9 & Yakutat, AK & 59.52 & -139.67 & 10 \\
\hline Nashville, TN & 36.25 & -86.57 & 10 & Bethel, AK & 60.78 & -161.8 & 10 \\
\hline Desert Rock/Mercury, NV & 36.62 & -116.02 & 10 & $\begin{array}{l}\text { Anchorage International Air- } \\
\text { port/Pt. Campbe, AK }\end{array}$ & 61.17 & -150.02 & 10 \\
\hline Roanoke/Blacksburg, VA & 37.2 & -80.41 & 10 & McGrath, AK & 62.97 & -155.62 & 10 \\
\hline $\begin{array}{l}\text { Springfield Regional Airport, } \\
\text { MO }\end{array}$ & 37.23 & -93.4 & 9 & Nome Ap, AK & 64.5 & -165.43 & 10 \\
\hline $\begin{array}{l}\text { Oakland International Airport, } \\
\text { CA }\end{array}$ & 37.75 & -122.22 & 10 & Fairbanks, AK & 64.82 & -147.87 & 9 \\
\hline Dodge City, KS & 37.77 & -99.97 & 10 & Kotzebue, AK & 66.87 & -162.63 & 10 \\
\hline Sterling(Washington Dulles), VA & 38.98 & -77.47 & 8 & Point Barrow, AK & 71.3 & -156.78 & 10 \\
\hline
\end{tabular}


Hawaii, Caribbean islands, and western tropical Pacific islands. Among these 93 stations, Pago Pago International Airport station was excluded in our dataset because it is the only one located in the Southern Hemisphere. Therefore, data from 92 radiosonde stations locating in the Northern Hemisphere were used in this paper. The geographical locations and available data accumulations of these 92 stations are listed in Table 1 . The longitudinal and latitudinal coverage of these 92 stations are $\left[170.22^{\circ} \mathrm{W}, 171.38^{\circ} \mathrm{E}\right]$ and $\left[6.97^{\circ} \mathrm{N}, 71.30^{\circ} \mathrm{N}\right]$, respectively. As shown in Table 1 of this paper and Fig. 1 in Wang and Geller (2003), the geographic distribution of these stations is somewhat irregular. For instance, 1) all the stations in the south of $10^{\circ} \mathrm{N}$ are islands in the Western Pacific; 2) between $15^{\circ}$ and $30^{\circ} \mathrm{N}$, the stations are either located in the Central Pacific or in the Carribbean islands; 3 ) in the mid-latitudes, they are located in the contiguous US; and 4) in north of $50^{\circ} \mathrm{N}$, the stations are solely located in Alaska.

Generally, at each station, the radiosonde observations are launched twice daily at 00:00 and 12:00 UT. In each sounding, pressure, temperature, relative humidity and horizontal winds are measured. The atmosphere is sampled at irregular height resolution, ranging from ten to hundreds meters. For convenience, in this paper the raw data were processed to have a regular height resolution $(50 \mathrm{~m})$ by applying a cubic spline interpolation to temperature and wind measurements. The maximum altitude of radiosonde observation corresponds to the burst height of the balloon, which is typically $25-30 \mathrm{~km}$. Thus we chose $25 \mathrm{~km}$ as the upper height limit of our analyses.

Employing the method presented by Zhang and Yi (2005, 2007), we can obtain the inertial GW parameters, including intrinsic frequency, amplitude, wavelength and wave energy density. Here we briefly introduce the method. Firstly, the background winds and temperature were removed by fitting a second-order polynomial to the vertical profiles of horizontal winds and temperature, respectively. Then, the residuals are regarded as fluctuation components. Typically, the fits are performed for two separate height ranges: a tropospheric segment from $2 \mathrm{~km}$ above the ground to $10 \mathrm{~km}$, and a low stratospheric segment from $18 \mathrm{~km}$ to the lower height between $25 \mathrm{~km}$ and the burst height of balloons. For stations with lower (lower than $12 \mathrm{~km}$ ) tropopause height, the upper limit height for the tropospheric segment is chosen to be $2 \mathrm{~km}$ below the tropospause. While for stations with higher (higher than $16 \mathrm{~km}$ ) tropopause height, the lower limit of the stratosphere segment is set to be $2 \mathrm{~km}$ above the tropopause. Moreover, since the height coverage for both the tropospheric and stratospheric segments are variable, only when the height coverage is larger than $5 \mathrm{~km}$ do we consider an acceptable measurement to be attained, and the data can be adopted.

Subsequently, we perform a Lomb-Scargle spectral analysis (Scargle, 1982) on the fluctuation components to determine the vertical wavelength. Obviously, the dominant vertical wavelengths derived from three different wave com- ponents (e.g., zonal wind, meridional wind and temperature) may be different. In our analysis the average value of these three dominant wavelengths is taken to be the wavelength of the extracted quasi-monochromatic gravity wave. Only when the relative standard deviation of the three dominant wavelengths is less than $20 \%$ do we consider a quasimonochromatic GW observed. Such a criterion will lead to smaller energy density and occurrence rate of GW events.

Having specified the vertical wavelength, we take a harmonic fitting to the fluctuation components to determine the wave amplitudes $\left[u^{\prime}, v^{\prime}, T^{\prime}\right]$ and phases for each wave component. The hodograph of the fitted horizontal wind disturbances is an ellipse, and the anti-clockwise or clockwise rotating hodographs indicate that the GW energy is, respectively, downward- or upward-propagating in the Northern Hemisphere. Wave kinetic and potential energies per unit mass are computed from

$E_{\mathrm{K}}=\frac{1}{2}\left(\overline{u^{\prime 2}}+\overline{v^{\prime 2}}+\overline{w^{\prime 2}}\right)$

and

$$
E_{\mathrm{P}}=\frac{1}{2} \overline{g^{2} T^{\prime 2}}
$$

respectively, where $T_{0}$ is the background temperature, which is attained from the second-order polynomial fits of the raw temperature profiles; $N$ is the buoyancy frequency, which can be calculated from the background temperature profile; $g$ is the gravitational acceleration; the over bar denotes an unweighted average over height. Although we do not have measurements of the vertical wind, it is much smaller than the horizontal wind (Venkat Ratnam et al., 2008) and thus neglected in our computation of wave kinetic energy.

\section{Results}

By using the approach introduced in Sect. 2, we calculate complete GW parameters, e.g., the intrinsic frequency $\Omega$, vertical wavelength, horizontal wavelength, wave amplitude, $E_{\mathrm{P}}, E_{\mathrm{K}}$ and $E_{\mathrm{T}}$ for each measurement. Generally, the ranges of GW parameters revealed by the present analyses are consistent with previous observations (Wang and Geller, 2003; Wang et al., 2005). In order to study the latitudinal variation of GW activity, the calculated GW energy is divided into $5^{\circ}$ bins in latitude.

\subsection{Lower stratospheric GW energy}

Figure 1 illustrates the latitudinal and monthly variations of GW potential, kinetic and total energy densities in the TLS. The latitudinal and seasonal variations of $E_{\mathrm{T}}$ in both troposphere and lower stratosphere are in good agreement with the results presented by Wang and Geller (2003). A salient 

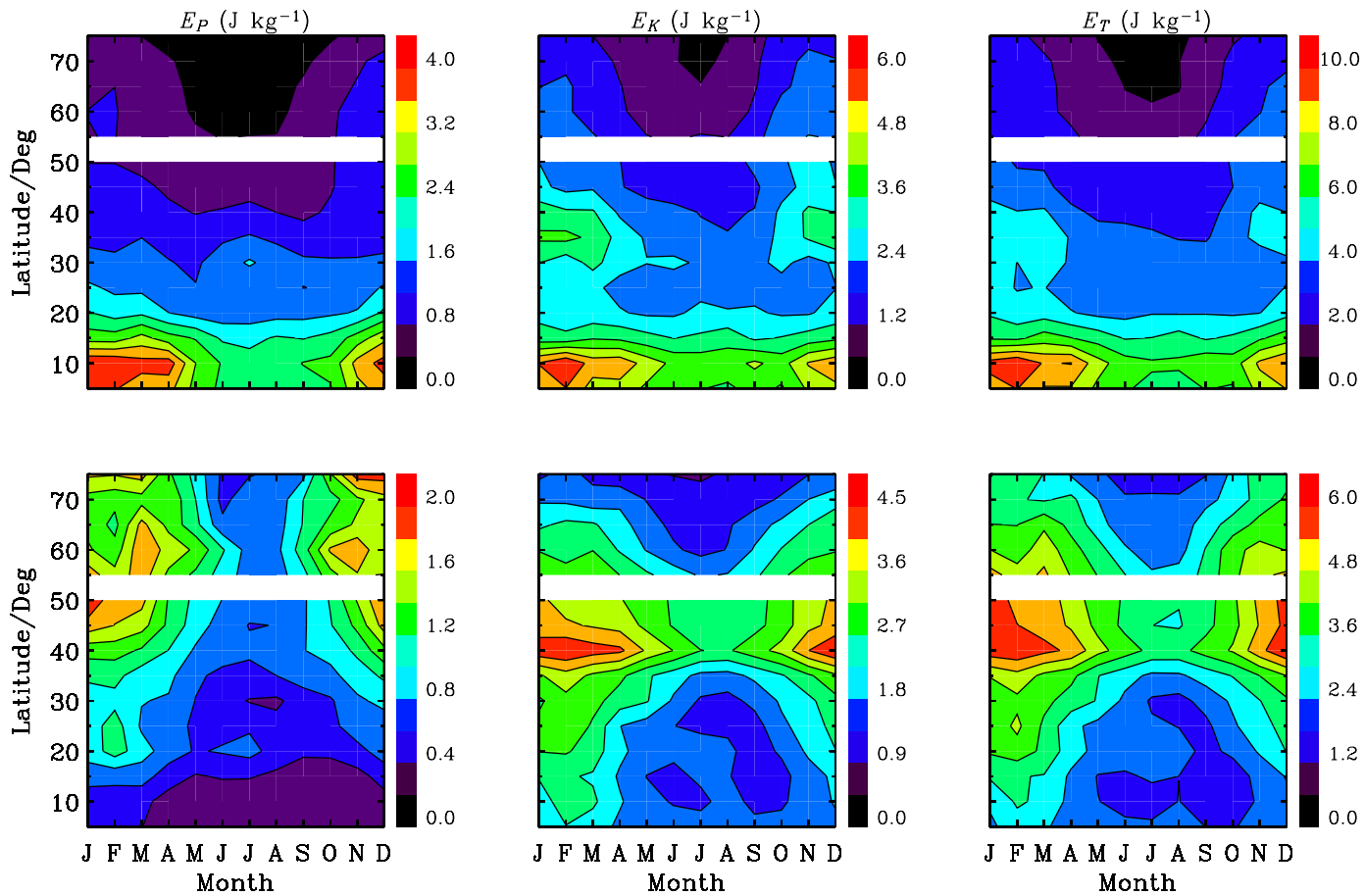

Fig. 1. Latitudinal and monthly variations of GW potential (left), kinetic (middle) and total (right) energy densities in the troposphere (lower panel) and lower stratosphere (upper panel). The blanks indicate the lack of available data.

feature of the lower stratospheric GW potential energy density $\left(E_{\mathrm{P}}\right)$ shown in Fig. 1 is its poleward decrease trend. Although due to the lack of latitudinal coverage of radiosonde stations, we can not assert the exact latitude where the lower stratospheric $E_{\mathrm{P}}$ has the maximum value, the $E_{\mathrm{P}}$ does exhibit a prominent peak value about $3.7 \mathrm{~J} \mathrm{~kg}^{-1}$ in the lowest latitudes of $5^{\circ} \mathrm{N}-10^{\circ} \mathrm{N}$. Moreover, the poleward decrease trend of $E_{\mathrm{P}}$ is steeper in the low latitudes than that in the high latitudes. The latitudinal variation of $E_{\mathrm{P}}$ in the lower stratosphere is consistent with satellite observations (Tsuda et al., 2000; Venkat Ratnam et al., 2004) and previous multi-station radiosonde observations (Wang and Geller, 2003; Wang et al., 2005). Moreover, the vertical wavelengths (not presented here) for GWs in the lower stratosphere derived from present radiosonde observations are usually less than $5 \mathrm{~km}$ and concentrate around $2 \mathrm{~km}$, which is in good agreement with satellite observations (Tsuda et al., 2000; Venkat Ratnam et al., 2004). These suggest that most of the latitudinal variation of GW activity can be revealed by the long-term multi-station radiosonde measurements. We would like to note that satellite observation results (Tsuda et al., 2000) were based on the lower stratospheric temperature variances with small vertical wavelengths, which were extracted by filtering from measured temperature profiles. In other words, the satellite observations mainly revealed the features of broad spectral GWs in the lower atmosphere, while the radiosonde observations presented in this paper in fact reflect the features of monochromatic GWs. Therefore, the consistence between the radiosonde and satellite observations also seems to imply that in the lower stratosphere, most small scale disturbances owe to monochromatic GWs.

The lower stratospheric $E_{\mathrm{P}}$ in the low latitudes has a strong seasonal cycle: the large and small values occur in winter and summer, respectively. A similar but rather weak seasonal variation can be observed in high latitudes, while in the middle latitudes no obvious seasonal variation can be found. This seasonal variation of GW $E_{\mathrm{P}}$ is different from that revealed by the satellite observations (Tsuda et al., 2000), in which a strong seasonal cycle of $E_{\mathrm{P}}$ was found in the middle latitudes. Such a difference may be due to geographical distribution of the radiosonde stations. All subpolar stations are located in Alaska. And all the data used in this paper in the south of $10^{\circ} \mathrm{N}$ are from stations located in islands in the Western Pacific, where deep convection with strong annual variation may be the main GW source.

As predicted by the linear GW theory, $E_{\mathrm{K}}$ in the lower stratospheric segment shown in Fig. 1 is generally larger than $E_{\mathrm{P}}$. Similar to $E_{\mathrm{P}}, E_{\mathrm{K}}$ in the lower stratosphere also exhibit an evident peak in low latitudes. More interestingly, besides the low latitudinal peak, $E_{\mathrm{K}}$ also has a weaker peak in the middle latitudes $\left(30^{\circ} \mathrm{N}-40^{\circ} \mathrm{N}\right)$, which is different from $E_{\mathrm{P}}$ and is likely caused by strong tropospheric jets in the middle latitudes. In fact, many previous observations have confirmed that the mid-latitude tropospheric jet can generate intensive GWs (Plougonven et al., 2003; Zhang and Yi, 2005, 2007, Zhang et al., 2008). And, recent satellite observations 
by Venkat Ratnam et al. (2004) have also confirmed a second maximum of $E_{\mathrm{P}}$ at midlatitudes during winter. More differences can be observed in their seasonal variations: The lower stratospheric $E_{\mathrm{K}}$ has obvious seasonal variation in almost all latitudes, including the middle latitudes. These differences imply that the variations of total gravity wave energy density, i.e. $E_{\mathrm{T}}$, may not be represented only by $E_{\mathrm{P}}$. Considering that the GW kinetic energy is usually larger than the potential energy, the kinetic energy should exert more contributions to the total GW energy than the potential energy.

Due to the contribution of $E_{\mathrm{K}}$, the total energy densities $E_{\mathrm{T}}$ in the lower stratosphere show two enhancement latitudinal regions. The strong one is in low latitudes, and the weak one is around the latitudes of $35^{\circ} \mathrm{N}$, potentially due to the strong tropospheric jet in middle latitudes, which has been seldom reported by satellite observation because of the difficulty in wind measurement. Another important feature of the lower stratospheric $E_{\mathrm{T}}$ is their evident seasonal variability in almost all latitudes. These are different from those of $E_{\mathrm{P}}$ and strongly suggest that in the study of lower stratospheric GW activity, it may be inappropriate to take only the potential energy into account, and, we should pay more attentions to the kinetic energy, total energy and their variations.

\subsection{Tropospheric GW energy}

It is obvious in Fig. 1 that the latitudinal variations of both $E_{\mathrm{P}}$ and $E_{\mathrm{K}}$ in the troposphere are completely different from those in the lower stratosphere. $E_{\mathrm{P}}$ in the troposphere exhibits an obvious poleward increase trend except for a second maximum value occurring around the latitude of $50^{\circ} \mathrm{N}$. The maximum $E_{\mathrm{P}}$ in the troposphere is about $2.6 \mathrm{~J} \mathrm{~kg}^{-1}$ occurring in latitudes of $70^{\circ} \mathrm{N}-75^{\circ} \mathrm{N}$ in winter. Moreover, an obvious seasonal variation of $E_{\mathrm{P}}$ can be observed in almost all latitudes. These are different from those in the lower stratosphere. $E_{\mathrm{K}}$ in the troposphere shows a prominent peak value about $5.0 \mathrm{~J} \mathrm{~kg}^{-1}$ in latitudes around $40^{\circ} \mathrm{N}$ in winter, which is believed to be yielded by strong middle latitudinal tropospheric jets in winter.

As a natural consequence, the latitudinal and seasonal variations of $E_{\mathrm{T}}$ in the troposphere are remarkably different from those in the lower stratosphere. In the troposphere, the $E_{\mathrm{T}}$ has a prominent peak around $45^{\circ} \mathrm{N}$. One can observe a strong seasonal variation of the $E_{\mathrm{T}}$ in all latitudes, especially in the middle and high latitudes, which are evidently different from those in the lower stratosphere. So striking differences between GW activity in the troposphere and lower stratosphere are not likely explained only by the background wind Doppler shifting due to strong tropospheric jets in the middle latitudes as proposed by Vincent and Alexander (2000), especially in the low latitudes, where the tropospheric jet is usually weak.

\section{Discussion}

Many efforts have been carried out to account for the low latitudinal peak of the lower stratospheric $E_{\mathrm{P}}$. Alexander et al. (2002) attributed such a peak to a natural consequence of the latitudinal variation in the Coriolis parameter $f$, which controls the lower limit for GW intrinsic frequency $\Omega$. Based on the dispersion relation of inertial GW, Alexander et al. (2002) showed that the intrinsic frequency and vertical group velocity of vertically propagating inertial GWs can be smaller in the lower latitudes due to the smaller value of the Coriolis parameter $f$. Consequently, they suggested that inertial GWs have more chance to be observed in the lower latitudes, because these waves may stay longer in the stratosphere before they propagate out of the observational altitudes. But, it should be emphasized that according to above interpretation, the lower $f$ at low latitudes only implies that GWs at low latitudes have a larger probability to be captured by a single radiosonde measurement rather than that GWs at low latitudes have larger energy. However, multi-station observations by Zhang and Yi (2007) indicated that in the troposphere, which was extensively regarded as the main GW source regions, the GW occurrence rates (defined as the ratio of the number of GW events to that of acceptable measurements) in the low-middle latitudes have almost the same value of about $50 \%$ and have no obvious latitudinal variation. Similar results (not shown) can also be obtained from the presented data set. Most recently, Chun et al. (2007) examined the convection sources in the tropical region $\left(30^{\circ} \mathrm{S}-\right.$ $30^{\circ} \mathrm{N}$ ) by analyzing high-resolution Global Cloud Imagery (GCI) and 6-hourly NCEP-NCAR reanalysis data. Their study suggested that the equatorial peak of $E_{\mathrm{P}}$ revealed by satellite observations resulted mainly from latitudinal variations of the convective source rather than those of Coriolis parameter. Thus, it is likely that the equatorial peak of GW potential energy was mainly caused by strong convection instead of larger occurrence rate of GWs in the low latitudes.

The difference between the latitudinal distributions of $E_{\mathrm{K}}$ and $E_{\mathrm{P}}$ in the lower stratosphere may also be attributed to the latitude distribution of GW sources. It is well known that besides topographic generation, strong convection, tropospheric jets and polar night jets also play important roles in the excitation of GWs in, respectively, the low, middle and high latitudes. Furthermore, a simulation study (Huang et al., 2002) indicated that, when a GW was newly excited by a thermal (momentum) source, large $E_{\mathrm{P}}\left(E_{\mathrm{K}}\right)$ could happen before the occurrence of large $E_{\mathrm{K}}\left(E_{\mathrm{P}}\right)$. Therefore, the latitudinal distributions of $E_{\mathrm{K}}$ and $E_{\mathrm{P}}$ could be different due to the latitudinal dependence of different sources. In middle latitudes, the tropospheric jet can generate intensive GWs (Plougonven et al., 2003; Zhang and Yi, 2005, 2007; Zhang et al., 2008) with very large kinetic energy, which has been confirmed by VHF radar (Murayama et al., 1994) and intensive radiosonde observations (Zhang et al., 2008). Additionally, according to the GW theory, the ratio of $E_{\mathrm{K}}$ to $E_{\mathrm{P}}$ can 

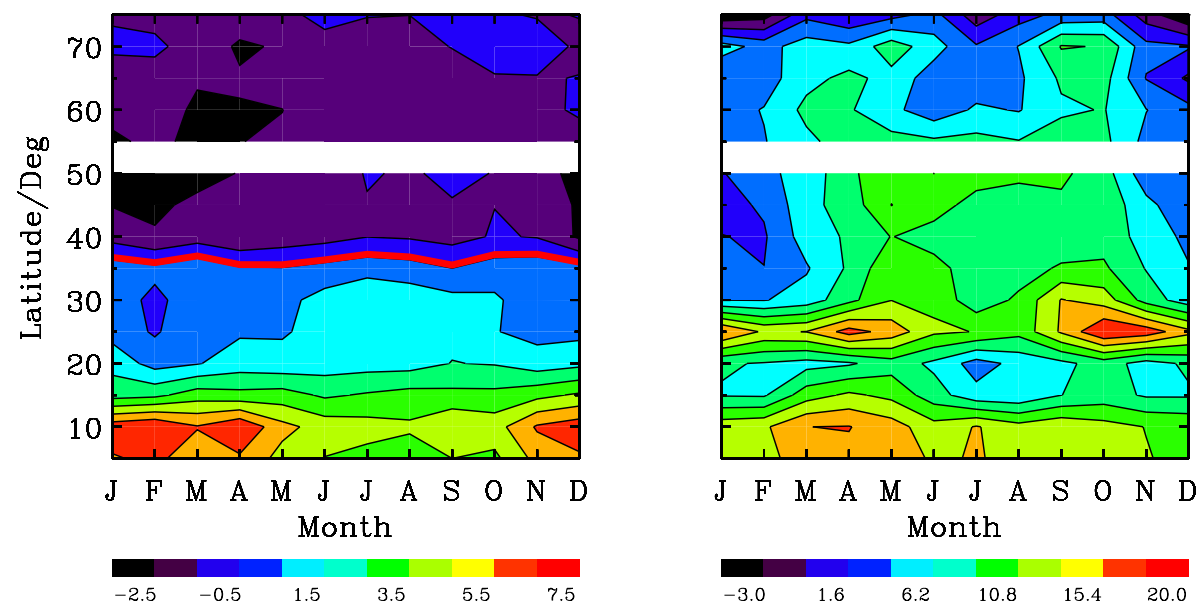

Fig. 2. Latitudinal and monthly variations of difference between the lower stratosphere and troposphere in total energy densities (in $\mathrm{J} \mathrm{kg}^{-1}$ ) of upward-propagating GWs (left panel). The difference is defined as the values in the lower stratosphere subtracted by those in the troposphere. The thick red curve around $35^{\circ} \mathrm{N}$ in the left panel marks the zero value. The right panel is similar to the left panel, but for the difference in mean number of observed upward-propagating GW events, which is calculated from the monthly mean number of observed upwardpropagating $\mathrm{GW}$ events in the lower stratosphere at each station subtracted by that in the troposphere.

be expressed in terms of GW intrinsic frequency and Coriolis parameter: $\frac{E_{\mathrm{K}}}{E_{\mathrm{P}}}=\frac{\Omega^{2}+f^{2}}{\Omega^{2}-f^{2}}$. This formula implies that at the same wave intrinsic frequency and potential energy density, GWs can carry more kinetic energy in the higher latitudes due to larger $f$. Thus, it is theoretically possible that GWs in higher latitudes may have larger kinetic and total energies. However, in the middle and high latitudes, due to absorption or reflection by jets, only part of the upward-propagating GWs excited by tropospheric jets can penetrate into the lower stratosphere, thus, $E_{\mathrm{T}}$ in the lower stratosphere still exhibits a prominent low latitude peak and a weak peak in middle latitudes in spite of a prominent middle latitude peak of $E_{\mathrm{K}}$ in the troposphere.

Another interesting issue is the causes and implications of the striking differences between GWs in the troposphere and lower stratosphere. To further study the differences, we plot, in Fig. 2, the latitudinal and monthly variations of the difference between the troposphere and lower stratosphere (defined as the values in the lower stratosphere subtracted by those in the troposphere) in $E_{\mathrm{T}}$ for upward-propagating GWs (left panel) and the mean number of upward-propagating GWs for each station (right panel). An interesting characteristic shown in the left panel in Fig. 2 is a clear zero line around the latitude of $35^{\circ} \mathrm{N}$, which exactly corresponds to the latitude of the second maximum value of $E_{\mathrm{k}}$ in the lower stratosphere and has never been reported before. In latitudes lower than $35^{\circ} \mathrm{N}, E_{\mathrm{T}}$ in the lower stratosphere is larger than that in the troposphere, strongly indicating that there are intensive GW sources lying in the intermediate region between the tropospheric and lower stratospheric segments, typically, in the height range of $10-18 \mathrm{~km}$. This can also be observed from the right panel of Fig. 2, in which we can see that except in the polar region (with latitudes higher than $70^{\circ} \mathrm{N}$ ), the upward-propagating GW events in the lower stratosphere are obviously more than those in the troposphere. Apparent differences in the number of upward-propagating GW events occur in two latitudinal regions, the first one is $5^{\circ} \mathrm{N}-10^{\circ} \mathrm{N}$ in March and April, and the second one is around $25^{\circ} \mathrm{N}$ in January, April, October and November. Since this difference is especially evident in the tropical and subtropical latitudes, we speculate the upper tropospheric convection rather than the Doppler shifting due to strong jets is the main cause responsible for the differences. These results further suggest that the intermediate region is an important source region for GWs, and should be given more attentions in future studies. While in latitudes higher than $35^{\circ} \mathrm{N}$, the situation reverses. This may result from the absorption of upward propagation GW energy by the tropospheric jets in the middle and high latitudes. Another possible cause for this latitudinal difference may be the latitudinal variation of the altitude distances of the lower stratospheric segment to the tropopause due to the latitudinal variation of tropopause heights. Moreover, the latitudinal location of the zero line seems to be invariant with season.

Similar to Fig. 2, the statistical results of downwardpropagating GWs are shown in Fig. 3. In almost all latitudes and months, the total energy densities of downwardpropagating GWs in the lower stratosphere are smaller than those in the troposphere. The right panel of Fig. 3 indicates that the downward-propagating GWs in the troposphere are generally more frequent than that in the lower stratosphere. An extremely evident region is around $25^{\circ} \mathrm{N}$ in May and $\mathrm{Oc}$ tober and November, which corresponds to the large value regions shown in the right panel of Fig. 2 and further confirms that the intermediate region is an important GW source region. 

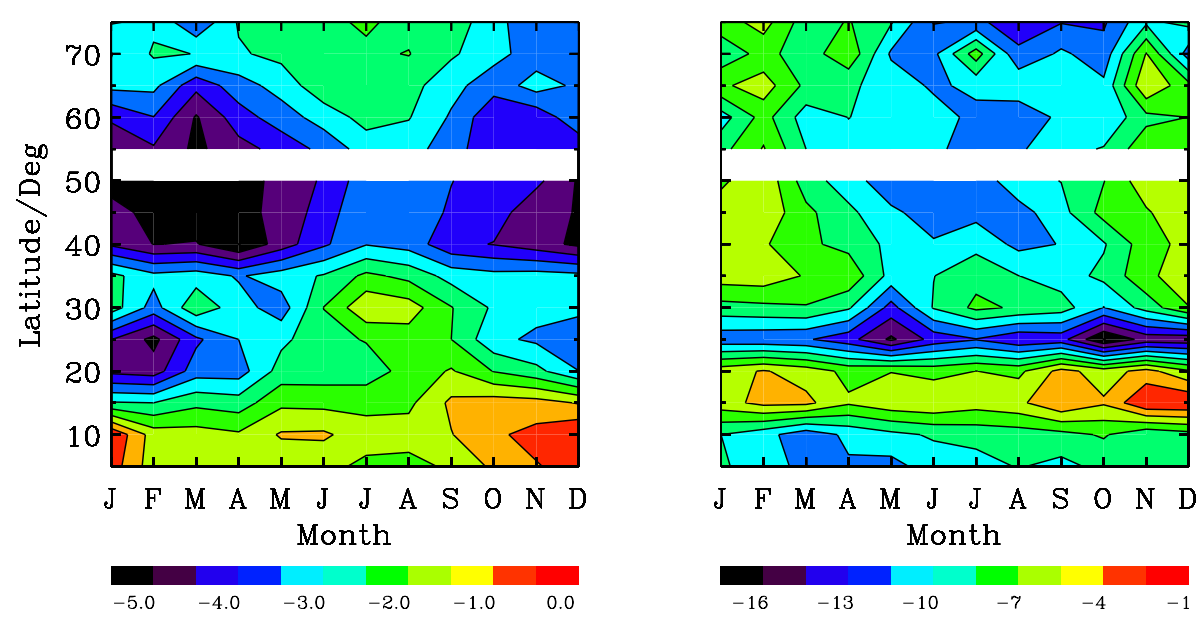

Fig. 3. Similar to Fig. 2, but for downward-propagating GWs.
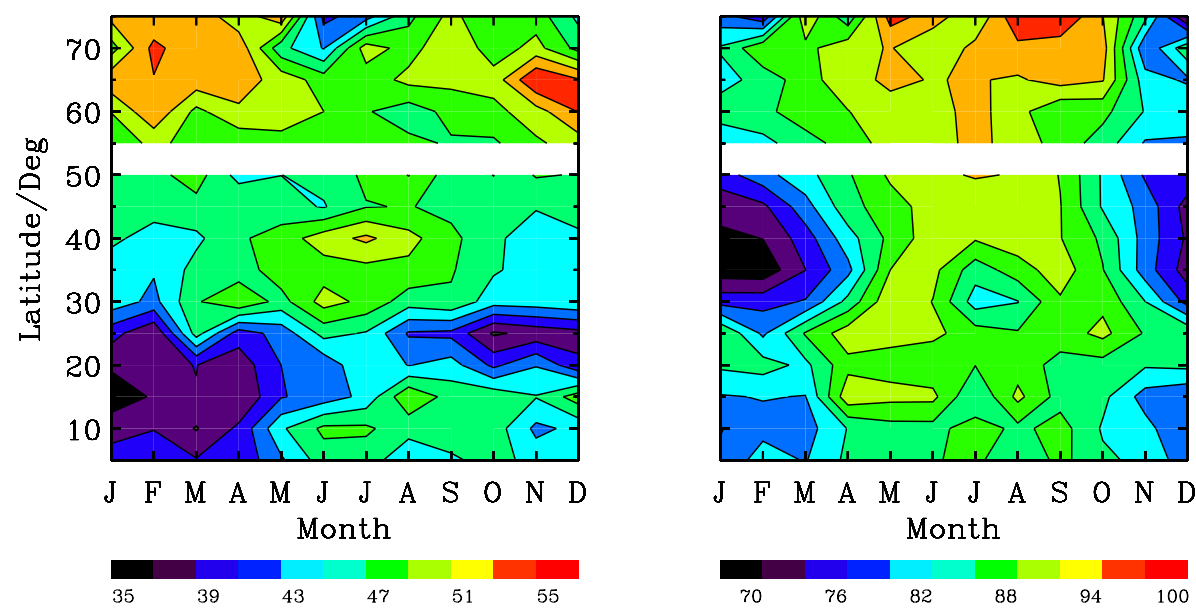

Fig. 4. Latitudinal and monthly variations of fractions (in percentage) for upward-propagating GWs in the troposphere (left) and lower stratosphere (right). The blanks indicate the lack of available data.

Finally, we present the latitudinal and seasonal variations of the fractions of upward propagation (defined as the ratio of the number of upward-propagating GWs to the total number of GW events) for GWs in the troposphere and lower stratosphere in Fig. 4. In the troposphere, in most latitudes and months the upward-propagation fractions are around 50\%, which is in good agreement with previous radiosonde observations (Wang et al., 2005; Zhang and Yi, 2005, 2007) and implies that most GW sources lie within the tropospheric segment. There are two low fraction regions, one is around $15^{\circ} \mathrm{N}$ in February, and the other is around $25^{\circ} \mathrm{N}$ in October. Recalling that around $25^{\circ} \mathrm{N}$ in October, as shown in Figs. 2 and 3 , the number of upward- (downward-) propagating GWs in the lower stratosphere is more (less) than that in the troposphere, we believe there are intensive GW sources within the intermediate segment at $25^{\circ} \mathrm{N}$ in October. A possible source may be the intensive upper tropospheric convection in monsoon season. Much larger fractions of upward propa- gation are observed in the lower stratosphere. In all latitudes and months, the fractions are larger than $70 \%$, indicating that most of the stratospheric GW sources are located in the lower heights, e.g., the troposphere. A minimum value about $70 \%$ emerges in the middle latitudes in winter due to the absorptions and/or reflections by the strong tropospheric jets, suggesting the important role of middle latitude tropospheric jets in determining the GW activity in the stratosphere.

Generally, our analyses revealed strikingly different latitudinal distributions of GW activity in the troposphere and lower stratosphere, and the drastically different latitudinal distributions obviously can not be fully explained by the background wind Doppler shifting, especially in low latitudes, where the tropospheric jets are believed to be weak. On the other hand, although GWs were launched in the lower stratosphere in many previous middle and upper atmospheric modeling works, recent numerical experiments and comparisons with observations (Warner and McIntyre, 2001; Ern et 
al., 2006; Fröhlich et al., 2007) suggested that in order to reproduce more realistic dynamic and thermal structures in the middle and upper atmosphere, the launching height of the prescribed GWs should be in the troposphere with a typical value at about $5 \mathrm{~km}$. Furthermore, Ern et al. (2006) and Fröhlich et al. (2007) emphasized that the launch height in the troposphere could provide a longitudinal filtering particularly due to the subtropical jets and this could not be achieved if the GWs were launched in the lower stratosphere. These numerical efforts indicated that the source parameterization of GWs in the troposphere can not be replaced by that in the lower stratosphere, indicating the significance of comprehensive understanding of the tropospheric GW activities.

\section{Summary}

Aiming at investigating the latitudinal and seasonal variations of GWs in the TLS, we analyzed 10 years (19982007) of radiosonde data over 92 United States stations in the Northern Hemisphere. The primary conclusions are summarized as follows:

The latitudinal variation of GW potential energy density in the lower stratosphere presented in this paper are in good agreement with satellite observations, indicating that most of the latitudinal variation of GW activity can be revealed by the long-term multi-station radiosonde observations. Due to the irregular geographical distribution of the radiosonde stations, the seasonal variation revealed by present radiosonde observations is somewhat different from that revealed by satellite observations.

GW kinetic and total energy densities in the stratosphere have a second maximum in middle latitudes, and seasonal variation of the total energy density can be observed in almost all latitudes. A possible explanation is the strong midlatitude tropospheric jets in winter can generate intensive GWs (Plougonven et al., 2003; Zhang and Yi, 2005, 2007; Zhang et al., 2008). These results are different from those of the potential energy density and are believed to be closely linked with the latitudinal dependence of GW sources. Moreover, the evident differences between the GW kinetic and potential energies in the lower stratosphere suggest that in order to fully understand the global GW activity, the contributions of GW kinetic energy and its geographical and seasonal variations should be fully included.

The latitudinal distribution of GW energy in the troposphere is distinctly different from that in the lower stratosphere. Obviously, so striking a difference cannot be fully accounted for only by the Doppler shifting due to the tropospheric jets in middle latitudes and polar night jets in high latitudes, indicating the significance of a comprehensive understanding of the tropospheric GW activity. In order to fully understand the difference between GWs in the troposphere and lower stratosphere, we should also consider the geographical distribution and seasonal variation of GW source in the lower atmosphere. Additionally, the latitudinal variation of the altitude distances of the lower stratospheric segment to the tropopause is another possible cause responsible for this difference.

The difference of the upward-propagating GWs in the troposphere and lower stratosphere displays a clear zero line around the latitude of $35^{\circ} \mathrm{N}$, which exactly corresponds to the latitude of the second maximum value of $E_{\mathrm{k}}$ in the lower stratosphere and has never been reported before. In latitudes lower than $35^{\circ} \mathrm{N}, E_{\mathrm{T}}$ in the lower stratosphere is larger than that in the troposphere, while in latitudes higher than $35^{\circ} \mathrm{N}$, the situation reverses.

A detailed comparison between the upward-propagating GWs in the troposphere and lower stratosphere suggest that the intermediate region between the tropospheric and lower stratospheric segments, typically, in the height range of 10$18 \mathrm{~km}$, is an important source region for GWs in the middle and upper atmosphere, and should be given more attention in the future studies.

Acknowledgements. The authors would like to thank the anonymous reviewers for their comments on the manuscript. This work was jointly supported by the National Natural Science Foundation of China through grant 40825013, 40731055 and 40774085, the Project 2007AA12Z177 from National High Technology Research and Development Program 863, the Program for Changjiang Scholars and Innovative Research Team in University (PCSIRT) and the Open Programs of State Key Laboratory of Space Weather.

Topical Editor P. Drobinski thanks two anonymous referees for their help in evaluating this paper.

\section{References}

Alexander, M. J., Tsuda, T., and Vincent, R. A.: Latitudinal variations observed in gravity wave effects with short vertical wavelengths, J. Atmos. Sci., 59, 1394-1404, 2002.

Alexander, S. P., Tsuda, T., Kawatani, Y., and Takahashi, M.: Global distribution of atmospheric waves in the equatorial upper troposphere and lower stratosphere: COSMIC observations of wave mean flow interactions, J. Geophys. Res., 113, D24115, doi:10.1029/2008JD010039, 2008.

Allen, S. J. and Vincent, R. A.: Gravity-wave activity in the lower atmosphere: Seasonal and latitudinal variations, J. Geophys. Res., 100, 1327-1350, 1995.

Chun, H. Y., Goh, J. S., and Song, I. S.: Latitudinal variations of the convective source and propagation condition of inertio-gravity waves in the tropics, J. Atmos. Sci., 64, 1603-1618, 2007.

Eckermann, S. and Preusse, P.: Global measurements of stratospheric mountain waves from space, Science, 286, 1534-1537, 1999.

Ern, M., Preusse, P., and Warner, C. D.: Some experimental constraints for spectral parameters used in the Warner and McIntyre gravity wave parameterization scheme, Atmos. Chem. Phys., 6, 4361-4381, doi:10.5194/acp-6-4361-2006, 2006.

Fetzer, E. J. and Gille, J. C.: Gravity wave variance in LIMS temperatures. Part I: Variability and comparison with background winds, J. Atmos. Sci., 51, 2461-2483, 1994. 
Fröhlich, K., Schmidt, T., Ern, M., Preusse, P., de la Torre, A., Wickert, J., and Jacobi, Ch.: The global distribution of gravity wave energy in the lower stratosphere derived from GPS data and gravity wave modeling: Attempt and challenges, J. Atmos. Sol-Terr. Phys., 69, 2238-2248, 2007.

Gong, J., Geller, M. A., and Wang, L.: Source spectra information derived from U.S. high-resolution radiosonde data, J. Geophys. Res., 113, D10106, doi:10.1029/2007JD009252, 2008.

Hei, H., Tsuda, T., and Hirooka, T.: Characteristics of atmospheric gravity wave activity in the polar regions revealed by GPS radio occultation data with CHAMP, J. Geophys. Res., 113, D04107, doi:10.1029/2007JD008938, 2008.

Huang, C. M., Zhang, S. D., and Yi, F.: A numerical study on the nonlinear propagation of gravity wave packets excited by temperature disturbance, Chinese J. Space Sci., 22, 330-338, 2002.

Manzini, E. and McFarlane, N.: The effect of varying the source spectrum of a gravity wave parameterization in a middle atmosphere general circulation model, J. Geophys. Res., 103, 3152331539, 1998.

McLandress, C., Alexander, M. J., and Wu, D. L.: Microwave limb sounder observations of gravity waves in the stratosphere: A climatology and interpretation, J. Geophys. Res., 105, 1194711967, 2000.

Murayama, Y., Tusda, T., and Fukao, S.: Seasonal variation of gravity wave activity in the lower atmosphere observed with the $\mathrm{Mu}$ radar, J. Geophys. Res., 99, 23057-23069, 1994.

Plougonven, P., Teitelbaum, H., and Zeitlin, V.: Inertial gravity wave generation by the tropospheric mid-latitude jet as given by the Fronts and Atlantic Storm-Track Experiment radio sounding, J. Geophys. Res., 108(D21), 4686, doi:10.1029/2003JD003535, 2003

Scargle, J. D.: Studies in astronomical time series analysis II, statistical aspects of spectral analysis of irregularly spaced data, Astrophys. J., 263, 835-853, 1982.

Shao Dong Zhang, Chunming Huang, and Fan Yi: Radiosonde observations of vertical wave number spectra for gravity waves in the lower atmosphere over Central China, Ann. Geophys., 24, 3257-3265, doi:10.5194/angeo-24-3257-2006, 2006.

Shao Dong Zhang, Fan Yi, Chun Ming Huang, and Ze Yu Chen: Intensive radiosonde observations of gravity waves in the lower atmosphere over Yichang $\left(111^{\circ} 18^{\prime} \mathrm{E}, 30^{\circ} 42^{\prime} \mathrm{N}\right)$, China, Ann. Geophys., 26, 2005-2018, doi:10.5194/angeo-26-2005-2008, 2008.
Tsuda, T., Nishida, M., Rocken, C., and Ware, R. H.: A global morphology of gravity wave activity in the stratosphere revealed by the GPS occultation data (GPS/MET), J. Geophys. Res., 105, 7257-7273, 2000.

Venkat Ratnam, M., Babu, A. N., Rao, V. V. M. J., Rao, S. V. B., and Rao, D. N.: MST radar and radiosonde observations of inertia-gravity wave climatology over tropical stations: Source mechanisms, J. Geophys. Res., 113, D07109, doi:10.1029/2007JD008986, 2008.

Venkat Ratnam, M., Tetzlaff, G., and Jacobi, C.: Study on stratospheric gravity wave activity: Global and seasonal variations deduced from the Challenging Mini-satellite Payload (CHAMP)GPS Satellite, J. Atmos. Sci., 61, 1610-1620, 2004.

Vincent, R. A. and Alexander, M. J.: Gravity waves in the tropical lower stratosphere: An observational study of seasonal and interannual variability, J. Geophys. Res., 105, 17971-17982, 2000.

Wang, L. and Geller, M. A.: Morphology of gravity-wave energy as observed from 4 years (1998-2001) of high vertical resolution U.S. radiosonde data, J. Geophys. Res., 108, 4489, doi:10.1029/2002JD002786. 2003.

Wang, L., Geller, M. A., and Alexander, M. J.: Spatial and temporal variations of gravity wave parameters. Part I: Intrinsic frequency, wavelength, and vertical propagation direction, J. Atmos. Sci., $62,125-142,2005$.

Warner, D. C. and McIntyre, M. E.: An ultrasimple spectral parameterization for nonorographic gravity waves, J. Atmos. Sci., 58, 1837-1857, 2001.

Wu, D. L. and Waters, J. W.: Gravity-wave-scale temperature fluctuations seen by the UARS MLS, Geophys. Res. Lett., 23, 32893292, 1996.

Zhang, S. D. and Yi, F.: A statistical study of gravity waves from radiosonde observations at Wuhan $\left(30^{\circ} \mathrm{N}, 114^{\circ} \mathrm{E}\right)$ China, Ann. Geophys., 23, 665-673, doi:10.5194/angeo-23-665-2005, 2005.

Zhang, S. D. and Yi, F.: Latitudinal and seasonal variations of inertial gravity wave activity in the lower atmosphere over central China, J. Geophys. Res., 112, D05109, doi:10.1029/2006JD007487, 2007. 